\section{Plastic Biodegradable Mulches Reduce Weeds and Promote Crop Growth in Day-neutral Strawberry in Western Washington}

Lisa W. DeVetter ${ }^{1,5}$, Huan Zhang ${ }^{2}$, Shuresh Ghimire², Sean Watkinson ${ }^{3}$, and Carol A. Miles ${ }^{4}$

Department of Horticulture, Northwestern Washington Research and Extension Center, Washington State University, 16650 State Route 536, Mount Vernon, WA 98273

Additional index words. Fragaria $\times$ ananassa, plasticulture, plastic mulch, paper mulch, growth analysis

Abstract. Day-neutral strawberry (Fragaria $\times$ ananassa) is typically grown in plasticulture production systems that use black polyethylene (PE) mulch for weed management and promotion of crop growth and yield. The objectives of this research were to evaluate several commercial plastic and paper biodegradable mulch (BDM) products [Bio360, Experimental Prototype (Exp. Prototype), and WeedGuardPlus] in comparison with standard black PE mulch and bare ground cultivation in day-neutral strawberry grown in an annual system in northwestern Washington. Mulch performance [as percent visual cover (PVC)], weed suppression, marketable yield, plant biomass, and fruit quality were evaluated in 'Albion' and 'Seascape' strawberry grown in 2014 and 2015 . PVC measured at the end of the production season was lowest for the Exp. Prototype (8\%) in 2014 and was greatest for Bio360 (90\%), WeedGuardPlus (90\%), and PE $(98 \%)$. In 2015 , PVC at the end of the production season was again lowest for Exp. Prototype (62\%), followed by WeedGuardPlus (64\%), Bio360 (93\%), and PE mulch (97\%). Overall, weed pressure was higher in 2015 relative to 2014 and was greatest in the bare ground treatment in both years of the study. By the end of the 2015 season, weed cover in the bare ground treatment was $95 \%$, followed by WeedGuardPlus (50\%), Exp. Prototype $(34 \%)$, PE (25\%), and Bio360 (15\%). Yield showed year and cultivar effects and was higher in mulched treatments. Plant biomass showed varying effects; root biomass was lowest in 'Seascape' in 2015 under the bare ground treatment and greatest under Bio360, which was similar to PE mulch and WeedGuardPlus. Leaf biomass was lowest in the bare ground treatment and highest in mulched treatments (except in 2015, when leaf biomass was intermediate for plants grown with WeedGuardPlus). Crown biomass showed a similar trend and was overall greater for plants grown in mulched treatments except for Bio360 in 2014, which was the same as the bare ground treatment. Overall, fruit quality was maintained among strawberry grown with BDMs, with soluble solids concentration (SSC, \%) and titratable acidity (TA) being the only variables to show treatment effects. SCC tended to be lower in fruit from bare ground plots. TA was different for 'Seascape' in 2015 with fruit from bare ground and Exp. Prototype treatments having higher TA than the PE treatment. This study demonstrates that BDMs can be comparable to PE mulch in terms of performance and impacts on crop productivity in day-neutral strawberry, suggesting that BDMs could be a viable alternative to PE mulch for strawberry growers in the Pacific Northwest.

Total U.S. strawberry (Fragaria $\times$ ananassa) production was estimated to be 1.59 million $\mathrm{t}$ from 21,245 ha in 2016 [National Agricul-

Received for publication 22 Aug. 2017. Accepted for publication 10 Oct. 2017.

This work was funded by Washington State University's Emerging Research Issues program.

We gratefully acknowledge the assistance of Curtis Faustich, Rachel Rudolph, Rachel Weber, Matt Arrington, and China Moss for project assistance. ${ }^{1}$ Assistant Professor.

${ }^{2}$ Graduate Research Assistants.

${ }^{3}$ Scientific Assistant.

${ }^{4}$ Professor.

${ }^{5}$ Corresponding author. E-mail: lisa.devetter@wsu. edu.

1700 production of processing strawberry declines because processors are increasingly buying cheaper strawberries from California. Consumption and value of fresh-market dayneutral strawberry is increasing, however, with the value of fresh market strawberry production in Washington and Oregon increasing $43 \%$ between the years 2000 and 2016 (NASS, 2001, 2017). Consequently, many PNW growers are exploring plasticulture production using day-neutral cultivars targeting the fresh market.

Black PE mulch is extensively used in plasticulture because of its low cost and ability to manage weeds, conserve soil moisture, modify soil temperatures, increase crop yields and quality, and promote on-farm profitability (Fernandez et al., 2001; Freeman and Gnayem, 2005; Garwood, 1998; Lament, 1993; Miles et al., 2012). These benefits extend to both conventional and organic production systems, as PE mulches may be used for weed management in organic agriculture as long as the mulch is completely removed from the field once the growing or harvest season is complete [ $\$ 205.206$ (United States Department of Agriculture; USDA, 2014a) and $\S 205.601$ (b)(2)(i-ii) (USDA, 2014b)]. Presently, plastic BDMs are not allowed in certified organic production, but may be a tool to enhance sustainability in nonorganic production systems (Miles et al., 2017).

Despite the horticultural and economic benefits of PE mulch, removal, and disposal imposes both financial and environmental problems. Removal and disposal of PE mulch can be costly (Galinato and Walters, 2012; Galinato et al., 2012; Ghimire and Miles, 2016; Lucas et al., 2008) and was estimated to be $\approx \$ 1100$ per hectare in strawberry systems in western Washington. These costs are expected to increase as the cost of labor increases (R. Sakuma, personal communication). To avoid these costs, some growers resort to stockpiling, landfilling, burying, or burning removed mulches, which causes hazards to the environment and human-health (Garthe and Kowal, 1993; Hakkarainen and Albertsson, 2004; Levitan, 2005). While mulch recycling is available in some regions, it is limited in the PNW and this adds to growers' disposal costs for transport and cleaning of plastic mulch (G. Jones, personal communication). The significant transportation and labor costs needed to recycle $P E$ mulch impede the adoption of plastic mulch recycling and the overall sustainability of plasticulture specialty crop production.

BDMs may minimize some of the economic, environmental, and human health impacts associated with PE mulches and their associated disposal (Kasirajan and Ngouajio, 2012; Miles et al., 2017). These materials are manufactured from feedstocks derived from fossil fuels plus natural materials (e.g., starch polysaccharides and cellulose, up to $20 \%$ of the BDM) (Jamshidian et al., 2010; Miles et al., 2017). BDMs are engineered to completely 
biodegrade within 2 years, with $90 \%$ of their mass released as $\mathrm{CO}_{2}$ and water and the remaining $10 \%$ residing in the soil as microbial biomass (according to International Organization for Standardization 17556 and ASTM D5988). BDMs are applied using the same field equipment as PE mulch and are designed to be functionally similar to $\mathrm{PE}$ mulch. BDMs have undergone extensive testing in vegetable production systems. Depending on the specific product, BDMs have been found to completely deteriorate within soils after 13 months of incorporation and produce yields comparable to crops grown with PE mulch (Cowan et al., 2013; Haapala et al., 2014; Li et al., 2014; Miles et al., 2012).

BDMs have not been tested widely in strawberry and could be a suitable alternative to $\mathrm{PE}$ mulch in expanding plasticulture production systems. Bilck et al. (2010) found white and black BDMs made from blends of cassava (Manihot esculenta) starch and polybutylene adipate-co-terephthalate (PBAT) maintained yield and berry quality relative to PE mulch in short-day 'Ventana' strawberry grown in Brazil. Mechanical properties measured 8 weeks after application showed BDMs had reduced tensile strength and elongation at break, whereas film rigidity was higher relative to PE mulch. However, the BDM films were found to provide adequate mulch functionality in terms of groundcover and maintenance of yield in this production system. Yield and fruit quality were similar to PE mulch in short-day 'Honor' and 'Camarosa' strawberry grown with five BDMs made from Mater-Bi (Novamont S.p.A, Novara, Italy) in Portugal (Costa et al., 2014). BDMs have also been studied as a tool to suppress weeds and enhance establishment of short-day 'Jewel' and 'Honeoye' strawberry grown in a perennial matted-row system (Weber, 2003). Black polymer (IP40 Black) and paper mulch (Planters paper; Ken-Bar, Inc., Reading, MA) were effective at reducing weeds, but limited runner production necessary for matted-row establishment.

Modification of soil temperature by mulches is an important aspect of strawberry production systems. White-on-black BDMs M2 and M3 (Mater-Bi) and M1 (Biomind; Polivouga, Albergaria-a-Velha, Portugal) in autumn-winter strawberry production showed $70 \%, 86 \%$, and $20 \%$ soil coverage, respectively, at the end of the crop cycle, whereas PE mulch had 100\% soil coverage (Andrade et al., 2014). Soil covered with these BDMs had 0.02 to $2.78{ }^{\circ} \mathrm{C}$ higher soil temperatures in the summer period at $15 \mathrm{~cm}$ depth than soils covered with PE mulch, which the authors of the study inferred was a key contributing factor to the reduced yields observed across all BDM-treated plots relative to PE. In other studies, soil treated with black BDMs (Ecoflex, BASF, Florham Park, NJ) overall showed a slightly lower soil temperature than low-density PE (LDPE, Pliant Corp., Schaumburg, IL) mulch at a depth of $1 \mathrm{~cm}$ in the soil (Ngouajio et al.,
2008). These studies show that different BDMs have different effects on soil temperature; the impact of BDMs on soil temperature will be an important factor in how well BDMs fit in strawberry production.

The objectives of this research were to evaluate several commercial plastic and paper BDM products and to compare them with standard black PE mulch and bare ground cultivation in day-neutral strawberry grown in an annual system in western Washington. Mulch performance, including deterioration and weed suppression ability, as well as impacts on plant growth, yield, and fruit quality were measured to assess mulch performance and suitability for commercial production systems.

\section{Materials and Methods}

Plot establishment and maintenance. The study was conducted at the Washington State University (WSU) Northwestern Washington Research and Extension Center in Mount Vernon, WA (lat. $48^{\circ} 26^{\prime} 28.9^{\prime \prime} \mathrm{N}$, long. $\left.122^{\circ} 23^{\prime} 44.1^{\prime \prime} \mathrm{W}\right)$. Soil is a field silt loam, characterized as a mixed, nonacid, and mesic Aquic Xerofluvent (USDA, 2017). The experimental design was a randomized complete block split-plot with five mulch treatments and two strawberry cultivars replicated four times. The main plot treatment consisted of three BDMs, PE mulch, and bare ground (Table 1). The subplot treatments consisted of dayneutral strawberry cultivars, Albion and Seascape. The experiment was carried out in 2014 and repeated in 2015 in an adjacent field (soil type was still a field silt loam). Main plot treatments were hand-applied to $6.1 \mathrm{~m}$-long raised bed plots in May 2014 and June 2015. Raised beds were formed using a mechanical bed shaper (Rain-Flo 2600; Rain-Flo Irrigation LLC., East Earl, PN). Resultant beds were $0.61 \mathrm{~m}$ wide, $0.25 \mathrm{~m}$ tall, spaced $4.3 \mathrm{~m}$ apart on the center; plots within a row were separated by $0.9 \mathrm{~m}$. Before mulch application, pressure-compensating drip tape $(20 \mathrm{~cm}$ emitter spacing, 1.3 LPH, Aqua-Traxx; Toro, Bloomington, $\mathrm{MN}$ ) was centered on the raised beds. Tensiometers (Irrometer, Riverside, CA) were installed in the third replicate (row) of the bare ground and PE treatments at depths of 30.5 and $45.7 \mathrm{~cm}$ and were used to schedule irrigation. All plots were irrigated when tensiometers averaged -30 kpa (HoashiErhardt and Walters, 2014).

After mulch application in May 2014 and June 2015, bare-root 'Albion' and 'Seascape' strawberries were planted in all treatments in holes that were punctured with a $41-\mathrm{cm}$ long dibble bulb and seed planter (DeWit Tools, TDI Brands, Jasper, IN). Resultant holes were $7.6 \mathrm{~cm}$ in diameter and $15.2 \mathrm{~cm}$ deep. The dibble was found to tear the paper mulch, so a knife with a $10-\mathrm{cm}$ long blade was first used to cut an " $X$ " shape in the mulch, which created four flaps that were folded and the dibble was subsequently used to create the planting holes. Planting holes were arranged in staggered double rows, with $25.4 \mathrm{~cm}$ between each twin row and $30 \mathrm{~cm}$ between plants within a row. Each plot contained 38 plants total, with 19 plants each of the cultivars Albion and Seascape. Any plants that failed to grow within 2 weeks after planting were replaced. All runners were removed from plants throughout the duration of the experiment and blossoms were removed for 6 weeks before being allowed to form fruit.

The site was managed according to the recommended guidelines for day-neutral strawberry grown in western Washington (Hoashi-Erhardt and Walters, 2014). A custom blend preplant fertilizer $(6 \mathrm{~N}-8.7 \mathrm{P}$ 16.6K; Wilbur-Elis Co., Burlington, WA) was broadcast at a rate of $20 \mathrm{~kg} \cdot \mathrm{ha}^{-1} \mathrm{~N} 2$ weeks before bed formation and planting in both years of the study. Supplemental fertilizer (20N-8.7P-16.6K; Plant Marvel Laboratories, Inc., Chicago Heights, IL) dissolved in water and injected through the irrigation system was provided beginning in July of both years at a rate of $5.6 \mathrm{~kg} \cdot \mathrm{ha}^{-1} \mathrm{~N}$ per week. On 24 July 2015, $56 \mathrm{~kg} \cdot \mathrm{ha}^{-1}$ of $\mathrm{MgSO}_{4}$ (Magriculture; Premier Magnesia, LLC., Waynesville, NC) was applied through fertigation, and on 3 and 10 Aug. 2015, foliar applications of $8 \% \mathrm{CaCl}_{2}$ (Phyta-Cal QC; CA Organic Fertilizers, Inc., Hanford, CA) were applied at $4.7 \mathrm{~L} \cdot \mathrm{ha}^{-1}$. Applications of $\mathrm{MgSO}_{4}$ and $\mathrm{CaCl}_{2}$ were made based on visual observations of symptoms indicating these nutrients were lacking and production guidelines (Hoashi-Erhardt and Walters, 2014).

Data collection. Soil temperature was recorded (HOBO U12 logger; Onset Computer, Bourne, MA) every $15 \mathrm{~min}$ throughout the growing season in 2014 and 2015. Probes

Table 1. Mulch treatments evaluated in 'Albion' and 'Seascape' strawberry grown in Mount Vernon, WA, 2014-15.

\begin{tabular}{lcc}
\hline Mulch product & Company & Composition $^{z}$ \\
\hline Bio360 & Dubois Agrinovation, Saint-Remi, & Mater-Bi + PBAT; biodegradable \\
& Quebec, Canada & and compostable; black; $20 \mu \mathrm{m}$ \\
WeedGuardPlus & Sunshine Paper Co. LLC, Aurora, & Cellulosic; biodegradable and \\
& CO & compostable; maroon; 230 $\mu \mathrm{m}$ \\
Experimental prototype & Custom Bioplastics, Burlington, & TPS and PHA; biodegradable and \\
& WA & compostable; black; 20 $\mu \mathrm{m}$ \\
Polyethylene & Poly Expert, Laval, Quebec, & Standard agricultural PE mulch; \\
& Canada & nondegradable; black; $20 \mu \mathrm{m}$ \\
\hline
\end{tabular}

${ }_{\mathrm{z}} \mathrm{PBAT}=$ polybutylene adipate terephthalate; $\mathrm{TPS}=$ thermoplastic starch $; \mathrm{PHA}=$ polyhydroxyalkanoate $\mathrm{PE}=$ polyethylene.

${ }^{\mathrm{y}}$ Exp. Prototype was reformulated to provide longer coverage in 2015; the specifics of the reformulation were not disclosed, as this was proprietary information of the mulch manufacturer. 
were installed in one replicate block to a depth of $10 \mathrm{~cm}$ and were $10 \mathrm{~cm}$ away from a plant crown. Mean air temperature, relative humidity, precipitation, and soil temperature (recorded at $5 \mathrm{~cm}$ depth) were collected every $15 \mathrm{~min}$ from a weather station located $0.7 \mathrm{~km}$ away and evaluated monthly from June through September of each year (WSU AgWeatherNet, 2017).

To assess mulch deterioration, visual observations of rips, tears, and holes were observed and recorded as PVC of the soil on the 15th and 30th of each month during the experiment. The percentage of weed cover was also recorded to assess weed suppression by the mulch treatment. PVC and weed cover were determined in a permanently designated $0.6 \times 0.9 \mathrm{~m}$ area in the center of each split plot. A fully intact mulch film received a PCV rating of $100 \%$. For both mulch PVC and weed cover measurements, a $1 \%$ measurement interval was used up to $5 \%$, and after that point a $5 \%$ measurement interval was used. All plots were hand-weeded after PVC and weed cover assessments were completed on 17 July 2014 and 23 and 24 July 2015, which returned all treatments to $0 \%$ weed cover.

Harvest was from 14 Aug. to 23 Sept. 2014 and from 17 Aug. to 5 Oct. 2015 (6 and 7 weeks, respectively). Ripe fruits were harvested by subplot three times per week; fruit were picked by hand and transported to a laboratory for sorting and weighing. Total marketable and unmarketable berry weight and percentage unmarketable fruit per subplot were recorded within $48 \mathrm{~h}$ after harvesting, with fruit being stored at $1.7{ }^{\circ} \mathrm{C}$ overnight as needed. Fruit were culled into the unmarketable category based on size (fruit $\leq 21 \mathrm{~mm}$ were culled), physical or developmental defects, and pest and disease damage. Each week during harvest, a 20berry subsample was collected per subplot and frozen at $-23{ }^{\circ} \mathrm{C}$ until later fruit quality analysis. Percent SSC, juice $\mathrm{pH}$, and TA (as percent citric acid) were determined from the subsample of fruit from each harvest week in 2014 and 2015; all fruit quality data were performed in triplicate and were averaged by treatment. Berries were thawed at room temperature $\left(\approx 21^{\circ} \mathrm{C}\right)$, blended in a 10 -speed 1.25-L capacity blender (Model \#6883 by Oster, Boca Raton, FL) for 30-60 s and then strained through a kitchen-grade fine mesh strainer followed by straining through two layers of cheesecloth to obtain a solids-free juice solution. SSC of juice was measured with a hand-held refractometer (REF-113; Index Instruments U.S., Inc., Kissimmee, FL). Juice $\mathrm{pH}$ and TA were determined simultaneously using a digital titrator that measured initial juice $\mathrm{pH}$ (HI-84532; Hanna Instruments, Woonsocket, RI) and titrated to an endpoint of $\mathrm{pH} 8.1$ using a solution of 0.1 $\mathrm{N}$ sodium hydroxide.

Dry biomass of strawberry plants was determined the week after the conclusion of harvest. In each year, four plants per subplot were harvested and separated by roots, leaves (petioles included), and crowns; remaining flowers and fruit were discarded and not included in biomass analyses. Plant material was dried at $70{ }^{\circ} \mathrm{C}$ for $5 \mathrm{~d}$ or until constant weight was achieved.

Statistical analysis. All data were subjected to the generalized linear mixed model procedure in SAS (Statistical Analysis System software, Ver. 9.3; SAS Institute, Inc., Cary, NC). The assumptions of normality and homogeneity of variances were assessed using the Shapiro-Wilk test $(W>0.80)$ and the Levene's test $(\alpha=0.05)$, respectively. Blocks were treated as random effects with mulch treatment as the fixed effect. Data were analyzed as a one-way analysis of variance with a least-squares mean option; a Tukey-Kramer adjustment for multiple comparisons was used for estimates and tests of significance $(\alpha=0.05)$. For PVC and weed data, no transformation satisfied the assumptions of normality and equality of variances; therefore, those data were nonparametrically analyzed using mixed models on rank transformed data. Untransformed means are reported. Cultivar and year effects were also assessed. Data are presented by cultivar when there was a cultivar effect and by year when analyses revealed a treatment by year interaction.

\section{Results}

Environmental data. Weather conditions from June through September were slightly warmer and drier in 2015 relative to 2014 (Table 2). Compared with 2014, average air temperature was 2 and $1{ }^{\circ} \mathrm{C}$ higher in June and July 2015, respectively, similar in August for both years, and $1.8^{\circ} \mathrm{C}$ higher in Sept. 2015. Relative humidity was generally lower throughout the growing season in 2015 $(76.5 \%)$ than in $2014(83.1 \%)$. Precipitation from June through September was $10.5 \mathrm{~mm}$ lower in 2015 (37.8 $\mathrm{mm})$ than in 2014 (27.3 $\mathrm{mm})$, with precipitation deficits occurring in June and July of 2015.

Table 2. Environmental and soil temperature data for day-neutral strawberry grown with different mulch treatments in Mount Vernon, WA, 2014 and 2015.

\begin{tabular}{|c|c|c|c|c|c|c|c|c|}
\hline \multirow[b]{2}{*}{ Variables $^{\mathrm{z}}$} & \multicolumn{4}{|c|}{2014} & \multicolumn{4}{|c|}{2015} \\
\hline & June & July & Aug. & Sept. & June & July & Aug. & Sept. \\
\hline Air temperature $\left({ }^{\circ} \mathrm{C}\right)$ & 15.1 & 17.8 & 18 & 15.8 & 17.1 & 18.8 & 17.9 & 14 \\
\hline Relative humidity (\%) & 82.3 & 80.7 & 84.0 & 85.3 & 76.2 & 75.0 & 72.7 & 81.9 \\
\hline Precipitation (mm) & 29.0 & 32.8 & 22.4 & 67.1 & 15.5 & 2.8 & 37.1 & 53.6 \\
\hline \multicolumn{9}{|l|}{ Soil temperature $\left({ }^{\circ} \mathrm{C}\right)^{\mathrm{y}}$} \\
\hline Bio360 & 19.1 & 20.8 & 20.2 & 16.9 & 21.8 & 22.4 & 20.2 & 15.6 \\
\hline WeedGuardPlus & 19.3 & 20.5 & 19.5 & 16.2 & 20.9 & 20.8 & 19.6 & - \\
\hline Exp. Prototype & 18.8 & 21.5 & 20.6 & 17.3 & 20.5 & 20.6 & 19.6 & - \\
\hline Plastic (PE) & 18.1 & 20.8 & 20.1 & 16.6 & 22.0 & 22.6 & 20.6 & - \\
\hline Bare ground (control) & 19.2 & 21.4 & 20.2 & $-^{x}$ & - & - & - & - \\
\hline Nontreatment $(5 \mathrm{~cm})$ & 18.3 & 19.8 & 19.6 & 16.1 & 18.8 & 19.9 & 19.2 & 16.6 \\
\hline
\end{tabular}

${ }^{\mathrm{z}}$ Environmental data (air temperature, relative humidity, precipitation, and nontreatment soil temperature) were collected from a weather station located $\approx 0.7 \mathrm{~km}$ from the experimental sites and were summarized every 15 min from June through September of both years. Data courtesy of WSU AgWeatherNet.

${ }^{y}$ Soil temperature under the mulches [Bio360, WeedGuardPlus, Experimental prototype, and polyethylene $(\mathrm{PE})]$ and bare-ground control were recorded every $15 \mathrm{~min}$ from probes installed in one replicate block to a depth of $10 \mathrm{~cm}$, and were $10 \mathrm{~cm}$ away from a plant; nontreated soil measurements were collected from the WSU AgWeatherNet station at a depth of $5 \mathrm{~cm}$ (soil surface had a mixed species grass groundcover).

${ }^{\mathrm{x}}$ Soil temperature data for the bare ground treatment in Sept. 2014 and in 2015 are not presented due to a logger malfunction; Sept. 2015 data also not reported due to a logger malfunction in the WeedGuardPlus, Experimental Prototype, and PE treatments. 


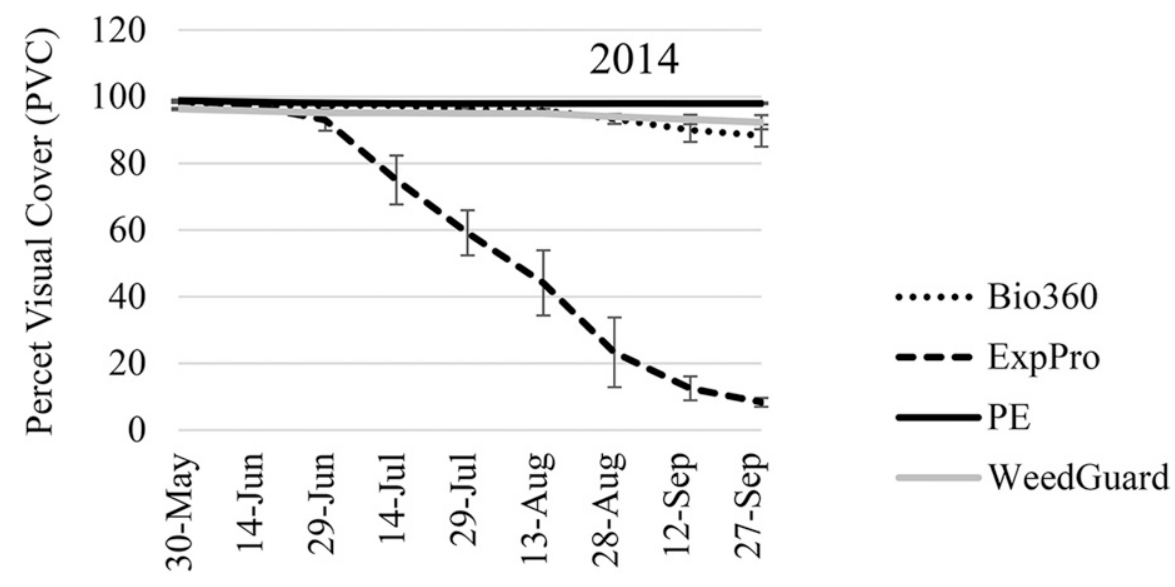

2015
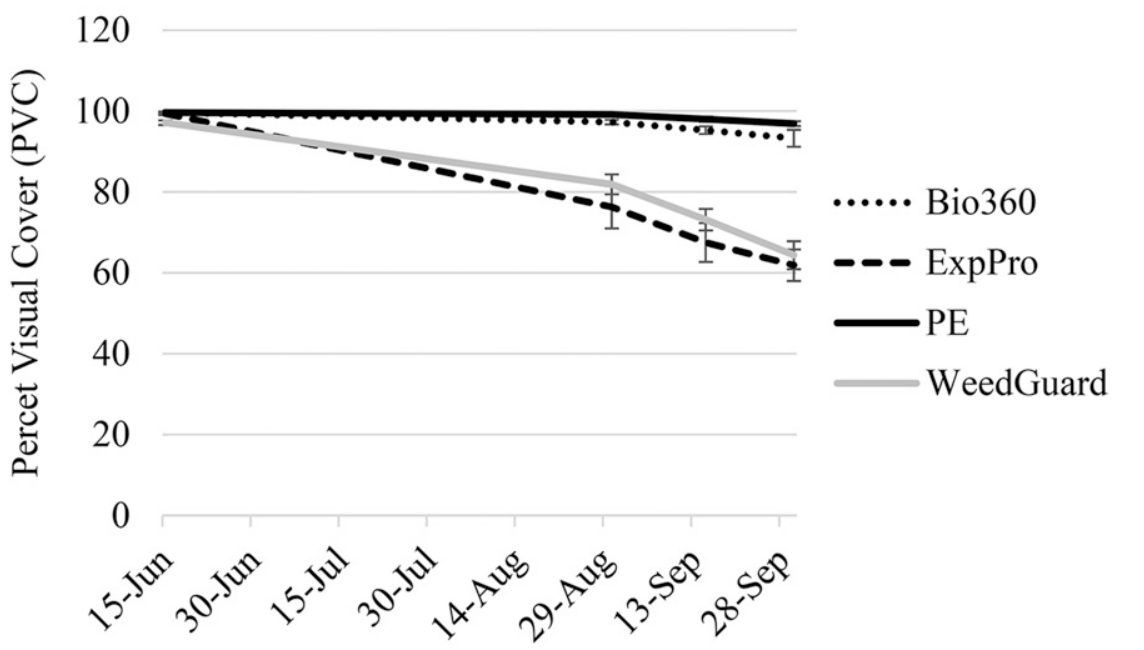

Fig. 1. Percent visual cover (PVC) of different mulch treatments applied to strawberry in Mount Vernon, WA, 2014-15.

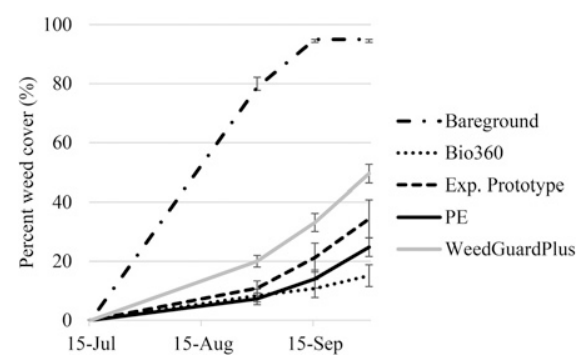

Fig. 2. Percent weed cover in strawberry grown with biodegradable and black polyethylene (PE) plastic mulches in Mount Vernon, WA, 2015.

differed because of treatment across all sampling dates $(P=0.0008)$ and weeds significantly increased from strawberry planting to the end of the last sampling date in all treatments $(P<0.0001)$ (Fig. 2$)$. By the end of the season, weed cover was greatest in the bare ground treatment (95\%) followed by WeedGuardPlus (50\%). Percent weed cover
'Seascape' marketable yield was greatest from plants treated with the Exp. Prototype and lowest in the bare ground plots in 2014, with the remaining treatments being similar $(P=0.05)$. In 2015 , marketable yield was greatest in the PE treatment followed by Bio360 and the Exp. Prototype, WeedGuardPlus, and the bare ground. 'Seascape' marketable fruit number only responded to treatments in 2015, where the pattern was the same as 2015 marketable yield. Unmarketable berry weight showed a year effect and was not different in 2014, averaging 49 and $65 \mathrm{~g} / \mathrm{plot}$ for 'Albion' and 'Seascape', respectively ( $P$ value $=0.56$ for 'Albion' and 0.675 for 'Seascape'). In 2015, 'Albion' unmarketable berry weight was greatest in the PE treatment (46 g/plot) followed by WeedGuardPlus (31 g/plot), with Bio360 and Exp. Prototype being similar to PE and WeedGuardPlus (39 and $37 \mathrm{~g} / \mathrm{plot}$, respectively); unmarketable berry weight was lowest in the bare ground treatment $(12 \mathrm{~g} / \mathrm{plot})(P<0.0001)$. The trend of differences in unmarketable berry weight was similar in 'Seascape', with unmarketable berry weight greatest in the PE treatment (59 g/plot) followed by WeedGuardPlus (43 g/plot), with Bio360 and Exp. Prototype being similar to PE and WeedGuardPlus (50 g/plot for both treatments); unmarketable berry weight was lowest in the bare ground treatment $(15 \mathrm{~g} / \mathrm{plot})(P<0.0001)$.

Dry biomass. Plant biomass differed because of cultivar, year, and treatment (Table 4). There was a year and cultivar effect for root biomass and a treatment effect only in 2015 for 'Seascape'. 'Seascape' root biomass was greatest under Bio360 mulch followed by WeedGuardPlus and PE, Exp. Prototype, and the bare ground control. There was no cultivar effect in both years of the study for leaf biomass, but there were effects due to year and treatment. Leaf biomass was higher across all treatments compared with bare ground control in 2014. In 2015, plants treated with plastic BDMs (Bio360 and Exp. Prototype) responded similarly to the PE treatment, whereas plants treated with WeedGuardPlus had a lower leaf biomass than other mulch treatments. Leaf biomass was lowest in the bare ground control. Crown biomass did not differ due to the cultivar in 2014 and was higher in the PE and Exp. Prototype treatments than the bare ground and Bio360 treatments, but was similar to WeedGuardPlus. In 2015, crown biomass differed by cultivar. 'Albion' treated with PE had the highest crown biomass and was similar to Bio360 and the Exp. Prototype, whereas crown biomass was similar among WeedGuardPlus, Bio360, and Exp. Prototype treatment plots. 'Seascape' crown biomass in 2015 was less responsive than 'Albion', with plants from all mulched plots producing higher biomass than bare ground.

Fruit quality. Only SSC showed a cultivar, year, and treatment difference, whereas fruit $\mathrm{pH}$ only differed due to year, and TA differed due to treatment only in 'Seascape' in 2015 (Table 5). 'Albion' SSC only differed in 2015 $(P=0.05)$, where it was higher in fruit harvested from the $\mathrm{PE}$ treatment when 
Table 3. Marketable fruit yield and number in 'Albion' and 'Seascape' strawberry grown with different mulch treatments in Mount Vernon, WA in 2014 and 2015.

\begin{tabular}{|c|c|c|c|c|c|c|c|c|}
\hline \multirow[b]{3}{*}{ Treatment } & \multicolumn{4}{|c|}{ Albion } & \multicolumn{4}{|c|}{ Seascape } \\
\hline & \multicolumn{2}{|c|}{$\begin{array}{c}\text { Marketable } \\
\text { yield/plot }(\mathrm{g})^{\mathrm{z}}\end{array}$} & \multicolumn{2}{|c|}{$\begin{array}{c}\text { Marketable fruit } \\
\text { number/plot }\end{array}$} & \multicolumn{2}{|c|}{$\begin{array}{c}\text { Marketable } \\
\text { yield/plot (g) }\end{array}$} & \multicolumn{2}{|c|}{$\begin{array}{c}\text { Marketable fruit } \\
\text { number/plot }\end{array}$} \\
\hline & 2014 & 2015 & 2014 & 2015 & 2014 & 2015 & 2014 & 2015 \\
\hline$\overline{\mathrm{Bio} 360}$ & $253 \mathrm{a}^{\mathrm{y}}$ & $181 \mathrm{a}$ & $19 \mathrm{a}$ & $15 \mathrm{ab}$ & $311 \mathrm{ab}$ & $190 \mathrm{~b}$ & 32 & $18 \mathrm{~b}$ \\
\hline GuardPlus & 259 a & $137.5 \mathrm{~b}$ & $17 \mathrm{a}$ & $11 \mathrm{c}$ & $316 a b$ & $144 \mathrm{c}$ & 30 & $13 \mathrm{c}$ \\
\hline & $1 \mathrm{a}$ & & $20 \mathrm{a}$ & $14 \mathrm{~b}$ & $10 \mathrm{a}$ & $202 \mathrm{~b}$ & 32 & $18 \mathrm{~b}$ \\
\hline Plasti & $295 \mathrm{a}$ & $200.7 \mathrm{a}$ & $22 \mathrm{a}$ & $17 \mathrm{a}$ & $322 \mathrm{ab}$ & $239 \mathrm{a}$ & 32 & $22 \mathrm{a}$ \\
\hline Bare ground (control) & $126 \mathrm{~b}$ & $80.0 \mathrm{c}$ & $9 \mathrm{~b}$ & $6 \mathrm{~d}$ & $257 \mathrm{~b}$ & $96 \mathrm{~d}$ & 25 & $8 \mathrm{~d}$ \\
\hline$P$ value & $<0.0001$ & $<0.0001$ & $<0.0001$ & $<0.0001$ & 0.05 & $<0.0001$ & 0.47 & $<0.0001$ \\
\hline
\end{tabular}

${ }^{\mathrm{z}}$ Marketable yield and fruit number determined from annual means of harvested fruit from $1.8 \mathrm{~m}^{2}$ subplots. ${ }^{\mathrm{y}}$ Means with the same letter within a column are not different due to treatment at $\alpha=0.05$; a TukeyKramer adjustment was used for multiple comparisons.

Table 4. Dry biomass of 'Albion' and 'Seascape' strawberry grown with different mulch treatments in Mount Vernon, WA in 2014 and 2015. Data are presented by year and cultivar when there was an interaction due to year or cultivar.

\begin{tabular}{|c|c|c|c|c|c|c|c|c|c|}
\hline \multirow[b]{3}{*}{ Treatment } & \multicolumn{4}{|c|}{ Roots $(\mathrm{g})$} & & & \multicolumn{3}{|c|}{ Crown $(\mathrm{g})$} \\
\hline & \multicolumn{2}{|c|}{ Albion } & \multicolumn{2}{|c|}{ Seascape } & \multicolumn{2}{|c|}{ Leaves $(\mathrm{g})$} & & \multicolumn{2}{|c|}{2015} \\
\hline & $\overline{2014}$ & 2015 & $\overline{2014}$ & 2015 & 2014 & 2015 & 2014 & Albion & Seascape \\
\hline Bio360 & 2.3 & 8.1 & 2.2 & $6.5 \mathrm{a}^{2}$ & $23.4 \mathrm{a}$ & $32.2 \mathrm{a}$ & $4.7 \mathrm{~b}$ & $3.7 \mathrm{abc}$ & $2.7 \mathrm{a}$ \\
\hline Wee & 3.2 & 7.4 & 2.2 & 6.0 & $25.1 \mathrm{a}$ & $26.9 \mathrm{~b}$ & $4.8 \mathrm{ab}$ & $3.3 \mathrm{bc}$ & $3.0 \mathrm{a}$ \\
\hline Exp. p 1 & 2.8 & 7.4 & 2.5 & $5.2 \mathrm{~b}$ & $26.1 \mathrm{a}$ & $32.9 \mathrm{a}$ & $5.5 \mathrm{a}$ & $4.1 \mathrm{ab}$ & $3.1 \mathrm{a}$ \\
\hline Plastic (PE) & 3.0 & 7.5 & 2.5 & $5.8 \mathrm{ab}$ & $27.1 \mathrm{a}$ & $34.2 \mathrm{a}$ & $5.6 \mathrm{a}$ & $4.4 \mathrm{a}$ & $2.7 \mathrm{a}$ \\
\hline Bare ground (control) & 3.1 & 5 & 2.9 & $3.9 \mathrm{c}$ & $16.8 \mathrm{~b}$ & $6.5 \mathrm{c}$ & $4.2 \mathrm{~b}$ & $2.9 \mathrm{c}$ & $2.0 \mathrm{~b}$ \\
\hline$P$ value & 0.34 & 0.19 & 0.63 & 0.002 & $<0.001$ & $<0.001$ & 0.003 & 0.006 & 0.023 \\
\hline
\end{tabular}

${ }^{\mathrm{z}}$ Biomass determined from four plants per cultivar subplot replicated four times; Means with the same letter within a column are not different due to treatment at $\alpha=0.05$; a Tukey-Kramer adjustment was used for multiple comparisons.

$\mathrm{PE}=$ polyethylene.

Table 5. Total soluble solids concentration ( $\mathrm{SSC}, \%$ ), juice $\mathrm{pH}$, and titratable acidity (as percent citric acid; CA, \%) of 'Albion' and 'Seascape' strawberry grown with different mulch treatments in Mount Vernon, WA in 2014 and 2015.

\begin{tabular}{|c|c|c|c|c|c|c|c|c|c|}
\hline \multirow[b]{3}{*}{ Treatment } & \multicolumn{4}{|c|}{ SSC (\%) } & & & \multicolumn{3}{|c|}{ CA (\%) } \\
\hline & \multicolumn{2}{|c|}{ Albion } & \multicolumn{2}{|c|}{ Seascape } & \multicolumn{2}{|c|}{$\mathrm{pH}$} & & \multicolumn{2}{|c|}{2015} \\
\hline & 2014 & 2015 & 2014 & 2015 & $\overline{2014}$ & 2015 & 2014 & Albion & $\overline{\text { Seascape }}$ \\
\hline$\overline{\text { Bio360 }}$ & $10^{z}$ & $8.0 a^{y}$ & $8.8 \mathrm{ab}$ & $8.1 \mathrm{a}$ & 3.6 & 3.4 & 0.72 & 0.66 & $0.65 \mathrm{ab}$ \\
\hline WeedGuardPlus & 9.3 & $8.1 \mathrm{ab}$ & $8.7 \mathrm{ab}$ & $7.9 \mathrm{a}$ & 3.6 & 3.5 & 0.68 & 0.64 & $0.66 \mathrm{ab}$ \\
\hline Exp. prototype & 9.3 & $8.3 \mathrm{ab}$ & $8.1 \mathrm{~b}$ & $7.6 \mathrm{a}$ & 3.6 & 3.5 & 0.67 & 0.67 & $0.71 \mathrm{a}$ \\
\hline Plastic (PE) & 10.1 & $8.6 \mathrm{a}$ & $9.0 \mathrm{a}$ & $7.7 \mathrm{a}$ & 3.5 & 3.4 & 0.7 & 0.62 & $0.64 \mathrm{~b}$ \\
\hline Bare ground & 9 & $7.5 \mathrm{~b}$ & $8.1 \mathrm{~b}$ & $6.3 \mathrm{~b}$ & 3.5 & 3.5 & 0.68 & 0.62 & $0.71 \mathrm{a}$ \\
\hline$P$ value & 0.28 & 0.05 & 0.05 & 0.0002 & 0.55 & 0.4 & 0.45 & 0.67 & 0.05 \\
\hline
\end{tabular}

${ }^{\mathrm{z}} \mathrm{SSC}(\%), \mathrm{pH}$, and CA (\%) determined from the mean of weekly 20-berry samples per subplot, performed in triplicate.

${ }^{\mathrm{y}}$ Means with the same letter within a column are not different due to treatment at $\alpha=0.05$; year and/or cultivar were combined when they were not statistically different; a Tukey-Kramer adjustment was used for multiple comparisons.

$\mathrm{CA}=$ citric acid; $\mathrm{PE}=$ polyethylene.

compared with the bare ground control, but was similar to the BDM treatments (Bio360, WeedGuardPlus, and Exp. Prototype). In 2014, 'Seascape' SSC was greatest in fruit harvested from the PE plots, but was similar to Bio360 and WeedGuardPlus. 'Seascape' SSC was lowest in the Exp. Prototype and bare ground control when compared with PE-treated plots. However, in 2015, 'Seascape' SSC was the same in fruit from all mulch treatments but higher than the bare ground control $(P=0.0002)$. Fruit $\mathrm{pH}$ was slightly higher in 2014 than $2015(P=0.03)$, but there were no cultivar nor treatment effects. TA only differed in 2015 for 'Seascape', where it was higher in fruit harvested from the Exp. Prototype and bare ground treatments compared with the PE treatment; both treatments were similar to Bio360 and WeedGuardPlus.

\section{Discussion}

Yield, plant biomass, and fruit quality of day-neutral strawberry grown with plastic BDMs were overall comparable to plants grown with PE mulch, whereas many of these variables were reduced for plants grown without mulch and were intermediate for plants grown with the paper BDM (WeedGuardPlus). Marketable yield and fruit number were greater in 2014 relative to 2015 because of the warmer, drier conditions during the 2015 June and July production period, which were less favorable for day-neutral strawberry production. Unmarketable berry weight was only different in 2015 , but was overall high across both years because of tarnished plant bug (Lygus lineolaris) feeding and rigorous culling for size. However, unmarketable berry weight was greater for all mulched treatments among both cultivars in 2015, which may be due to microclimate effects impacting crop development and is an area recommended for further study. Nevertheless, bare ground plots consistently had the lowest marketable yield and fruit number, which was consistent with previous studies that show productivity of strawberry and other horticultural crops are enhanced through mulch application because of reduced competition from weeds and a modified soil environment that is more favorable to plant growth and development (Anzalone et al., 2010; Diaz-Perez et al., 2005; Forcella et al., 2003; Moore, 1963; Touchaleaume et al., 2016; Waterer, 2010). Other studies comparing yield of strawberry grown with plastic BDMs show similar results and demonstrate that plants grown with plastic BDMs can produce yields equal to those grown with PE mulch (Bilck et al., 2010; Costa et al., 2014).

The current study showed cultivars can respond differently to BDM treatments. In general, 'Albion' appeared less sensitive to type of mulch application, with marketable yield and fruit number from plants treated with plastic BDMs being equal to those grown with PE mulch. Reduced yield from plants treated with the Exp. Prototype plastic BDM in 2015 can be attributed to greater weed pressure and resultant plant competition that may have been exacerbated by the warmer and drier environmental conditions that year. 'Seascape' had less consistent trends with regard to marketable yield and fruit number across the years of the study. Marketable yield was similar for all mulch treatments in 2014 but was strongly impacted by mulch treatment in 2015 when yield was greatest in plants treated with PE mulch, followed by the plastic BDM treatments, paper BDM, and was lowest in nonmulched plots. Taken together, these results suggest cultivar genetics may influence how dayneutral strawberry plants respond to different mulch treatments and that some cultivars may be more adaptable to systems that use BDMs. Similar to the yield results, plant biomass tended to be the lowest in bare ground, intermediate in the paper BDM treatment, and the greatest in PE and plastic BDM treatments. 'Albion' appeared less sensitive to mulch treatments with regard to root biomass, whereas 'Seascape' appeared less sensitive in regard to crown biomass, and both cultivars showed a similar response for leaf biomass. These results highlight how cultivar genetics lead to different developmental responses after mulch application and that environmental and weed pressure conditions of 2015 elicited more plant growth responses to mulch treatments when contrasted to 2014.

Root and leaf biomass were overall greater in 2015, which may have been an adaptive 
response to the environmental conditions and come at the cost of decreased fruit production. Perennial plants augment growth and development during periods of environmental stress, such as temperature and moisture stress, and mulching can alleviate plant stress by suppressing weeds, enhancing soil moisture, and improving soil temperatures. Kumar and Dey (2011) found that 'Chandler' strawberry plants grown with $\mathrm{PE}$ mulch, straw mulch, or bare ground had higher root growth when plants received irrigation $(100 \%, 80 \%$ and $60 \%$ of volume of water) and lower root growth under rainfed conditions in a subtemperate climate in India. Soil moisture content at $0-25 \mathrm{~cm}$ was $2.8 \%$ to $12.8 \%$ higher under PE mulch than bare ground. In a separate study by Taparauskiene and Miseckaite (2014) in a subhumid area of Lithuania, soil moisture content at $0-40 \mathrm{~cm}$ depth was higher under straw mulch $(18.0 \%)$ than under PE mulch $(16.5 \%)$ or bare ground $(16.2 \%)$, whereas strawberry fruit yield was $60 \%$ higher from plants grown with $\mathrm{PE}$ mulch than bare ground and $56 \%$ greater relative to plants grown with straw mulch.

Several studies have found that fruit quality is maintained or unchanged as a result of plastic BDM use (Bilck et al., 2010; Costa et al., 2014). However, Morra et al. (2015) found increased production of secondary metabolites (anthocyanins, flavanols, and polyphenols) and greater antioxidant activity in strawberry grown with plastic BDM (with Mater-Bi as the primary feedstock) relative to those grown with PE mulch. While the current study did not measure these secondary metabolites, there was an overall trend of lower SSC in fruits harvested from the bare ground treatment relative to mulched treatments. This difference may be due to the diurnal absorption and reradiation of heat energy from the dark-colored mulches, which could impact soil and canopy temperatures. Mulches may also change the quality and quantity of light energy being reradiated into the plant canopy, which may impact plant development and resultant fruit quality. Research has shown that mulch color can impact strawberry crop development and quality attributes of fruit. For example, in strawberry production in central Colombia, silver color mulch resulted in lower fruit $\mathrm{pH}, \mathrm{SSC}, \mathrm{TA}$, and dry biomass compared with red, blue, yellow, green, and black mulch treatments; the ratio of SSC to TA was highest with black mulch; fresh fruit weight and fruit length were highest with red mulch, which might be the result of absorbing more red and far-red light by phytochrome (Casierra-Posada et al., 2011; Kasperbauer et al., 2001). Wang et al. (1998) found that fruit of 'Northeaster' strawberry grown with red mulch had higher TA than fruit grown with black mulch.

All mulches reduced weed pressure relative to bare ground both years in the current study. This result is consistent with other studies that show plastic BDMs can provide efficacious weed suppression depending on their formulation and compatibility with the cropping system (Anzalone et al., 2010;
Cowan et al., 2014; Miles et al., 2012). Despite rapid changes in PVC of the Exp. Prototype in 2014, weed cover was comparable to the other mulched treatments and indicates weed suppression was adequate for the experimental conditions. Because of the rapid degradation of the Exp. Prototype in 2014, the mulch manufacturer re-formulated the mulch product, and consequently, the Exp. Prototype deteriorated less rapidly in 2015 (the specifics of the reformulation were not disclosed, as this was proprietary information of the mulch manufacturer). Exp. Prototype is made up of thermoplastic starch (TPS) and polyhydroxyalkanoate, which have been shown to have comparably high rates of above-ground disintegration (Cowan et al., 2013). Despite this, TPS has been successfully used in BDMs in strawberry production in Brazil (Bilck et al., 2010). Bio360 (formerly BioTelo) was observed to have high rates of PVC in both years of the experiment and was comparable to the $\mathrm{PE}$ control. Percent weed cover was low for Bio360 and was comparable to PE. This result was similar to a study with tomato (Lypocersicum esculentum) in Washington that included BioAgri mulch, which has a similar formulation as Bio360 (Miles et al., 2012). The starch in Bio360 is characterized as highly biodegradable while the PBAT component is characterized as having a low to moderate rate of biodegradation in soil (Brodhagen et al., 2015).

For WeedGuardPlus, PVC was reduced and percent weed cover increased in 2015 due to the occurrence of several windy days in July 2015 (maximum wind gusts surpassed $12.9 \mathrm{~km} \cdot \mathrm{h}^{-1}$, WSU AgWeathernet, 2017), which caused the WeedGuardPlus mulch to rip and tear along the buried edges of the raised bed, creating more exposed surfaces for degradation. Weber (2003) reported similar experiences when using Planters Paper in establishing matted-row strawberry in New York, where degradation occurred rapidly along buried edges of the planting beds and allowed wind to rip fragments of the mulch off the beds. Similarly, studies with WeedGuardPlus in tomato grown in Washington confirm this material is susceptible to ripping and has low rates of PVC later in the growing season (Cowan et al., 2014; Miles et al., 2012). Performance of WeedGuardPlus, however, varied based on location and production system, and was found to have higher deterioration in open-field production in Washington relative to Texas, and lower deterioration in a high tunnel environment relative to open-field ( $\mathrm{Li}$ et al., 2014). The primary feedstock in WeedGuardPlus is cellulose, a plant-derived polysaccharide that is intrinsically biodegradable and is characterized as having a moderately high rate of biodegradation in soils (Brodhagen et al., 2015; Sivan, 2011). These findings underscore that the environment and cropping system must be considered when selecting a BDM, as mulch performance will vary based on these factors. Additionally, while complete biodegradation is an important feature of BDMs, paper-based mulches may be too quick to degrade and consequently may not provide adequate soil surface coverage for strawberry, depending on the production environment and growers' goals.

\section{Conclusion}

The plastic BDMs studied in this experiment performed comparably to standard PE mulch and may provide a suitable alternative to PE mulch in plasticulture systems of dayneutral strawberry in the PNW. Bio360 was most similar to PE mulch in terms of PVC, weed suppression, and yield, indicating this material is compatible with commercial strawberry production systems and could replace PE mulch. Re-formulations of the Exp. Prototype could make it more compatible with the requirements of day-neutral strawberry production and additional testing of reformulated and new plastic BDMs (e.g., BASF Ecovio) is recommended. The question of in-soil biodegradation of these materials should also be pursued in future research, as there has been limited evaluation of in-soil biodegradation of plastic BDMs across different production systems and soil environments. It is important to note that while PE and paper BDMs are allowed in organic production, use of plastic BDMs is presently not permitted (Miles et al., 2017). Plastic BDMs may be a tool that enhances the sustainability of conventional strawberry production as a replacement for PE, but are also chemically and physically different from PE. Soil fumigation and concurrent BDM application is not allowed and producers should speak with mulch manufacturers if they have questions regarding how certain on-farm practices may impact plastic BDM performance. Overall, plastic BDMs are a promising tool for day-neutral strawberry growers and continued research on plastic BDMs as an alternative to PE could assist growers in reducing plastic waste generation while maintaining the profitability of their farm enterprises.

\section{Literature Cited}

Andrade, C., M. Palha, and E. Duarte. 2014. Biodegradable mulch films performance for autumn-winter strawberry production. J. Berry Res. 4(4): 193-202.

Anzalone, A., A. Cirujeda, J. Aibar, G. Pardo, and C. Zaragoza. 2010. Effect of biodegradable mulch materials on weed control in processing tomatoes. Weed Technol. 24(3):369-377.

Bilck, A.P., M.V. Grossmann, and F. Yamashita. 2010. Biodegradable mulch films for strawberry production. Polym. Test. 29(4):471-476.

Brodhagen, M., M. Peyron, C. Miles, and D.A Inglis. 2015. Biodegradable plastic agricultural mulches and key features of microbial degradation. Appl. Microbiol. Biotechnol. 99(3):1039-1056.

California Strawberry Commission. 2017. 2017 California strawberry acreage survey. 14 Aug. 2017. $<$ http://www.calstrawberry.com/Resources-News/ Industry-Reports $>$.

Casierra-Posada, F., E. Fonseca, and G. Vaughan. 2011. Fruit quality in strawberry (Fragaria sp.) 
grown on colored plastic mulch. Agron. Colomb. 29(3):407-413.

Costa, R., A. Saraiva, L. Carvalho, and E. Duarte. 2014. The use of biodegradable mulch films on strawberry crop in Portugal. Sci. Hort. 173:65-70.

Cowan, J.S., D.A. Inglis, and C.A. Miles. 2013. Deterioration of three potentially biodegradable plastic mulches before and after soil incorporation in a broccoli field production system in northwestern Washington. HortTechnology 23:849-858.

Cowan, J.S., C.A. Miles, P.K. Andrews, and D.A. Inglis. 2014. Biodegradable mulch performed comparable to polyethylene in high tunnel tomato (Solanum lycopersicum L.) production. J. Sci. Food Agr. 94:1854-1864.

Diaz-Perez, J.C., S.C. Phatak, D. Giddings, D. Bertrand, and H.A. Mills. 2005. Root zone temperature, plant growth, and fruit yield of tomatillo as affected by plastic film mulch. HortScience 40:1312-1319.

Fernandez, G.E., L.M. Butler, and F.J. Louws. 2001. Strawberry growth and development in an annual plasticulture system. HortScience 36:1219-1223.

Freeman, S. and N. Gnayem. 2005. Use of plasticulture for strawberry plant production. Small Fruits Rev. 4(1):21-32.

Forcella, F., S.R. Poppe, N.C. Hansen, W.A. Head, E. Hoover, F. Propsom, and J. McKensie. 2003. Biological mulches for managing weeds in transplanted strawberry (Fragaria $\times$ ananassa). Weed Technol. 17(4):782-787.

Galinato, S.P., C. Miles, and S. Ponnaluru. 2012. Cost estimates of producing fresh market fieldgrown tomato in western Washington. Washington State Univ. Ext. Publ. FS080E.

Galinato, S.P. and T.W. Walters. 2012. Cost estimates of producing strawberries in a high tunnel in western Washington. Washington State Univ. Ext. Publ. FS093E.

Garthe, J.W. and P.D. Kowal. 1993. Recycling used agricultural plastics. Penn. State Fact Sheet C-8.

Garwood, T. 1998. An economic analysis of matted row, plasticulture, and greenhouse production systems in North Carolina. N.C. State Univ., Raleigh, NC, MS Diss.

Ghimire, S. and C. Miles. 2016. Dimensions and costs of polyethylene, paper and biodegradable plastic mulch. Washington State Univ. Ext. Factsheet.

Haapala, T., P. Palonen, A. Korpela, and J. Ahokas. 2014. Feasibility of paper mulches in crop production-A review. Agr. Food Sci. 23:6079.

Hakkarainen, M. and A. Albertsson. 2004. Environmental degradation of polyethylene. Adv. Polym. Sci. 169:177-199.
Hoashi-Erhardt, W. and T. Walters. 2014. Growing day-neutral strawberries in western Washington. Washington State Univ. Fact Sheet FS132E.

Jamshidian, M., A. Tehrany, M. Imran, M. Jacquot, and S. Desobry. 2010. Poly-lactic acid: Production, applications, nanocomposites, and release studies. Compr. Rev. Food Sci. Food Saf. 9:552-571.

Kasirajan, S. and M. Ngouajio. 2012. Polyethylene and biodegradable mulches for agri-cultural applications: A review. Agron. Sustain. Dev. 32(2):501-529.

Kasperbauer, M., J. Loughrin, and S. Wang. 2001. Light reflected from red mulch to ripening strawberries affects aroma, sugar and organic acid concentrations. Photochem. Photobiol. Sci. 74(1):103-107.

Kumar, S. and P. Dey. 2011. Effects of different mulches and irrigation methods on root growth, nutrient uptake, water-use efficiency and yield of strawberry. Sci. Hort. 127(3):318-324.

Lament, W.J., Jr. 1993. Plastic mulches for the production of vegetable crops. HortTechnology 3:35-39.

Levitan, L. 2005. Reducing dioxin emissions by recycling agricultural plastics: Creating a viable alternative to open burning. Great Lakes Regional Pollution Prevention Roundtable, New York, NY.

Li, C., J. Moore-Kucera, C. Miles, K. Leonas, J. Lee, A. Corbin, and D. Inglis. 2014. Degradation of potentially biodegradable plastic mulch films at three diverse U.S. locations. Agroecol. Sust. Food 38:861-889.

Lucas, N., C. Bienaime, C. Belloy, M. Queneudec, F. Silvestre, and J.E. Nava-Saucedo. 2008. Polymer biodegradation: Mechanisms and estimation techniques-A review. Chemosphere 73(4):429-442.

Miles, C., L. DeVetter, S. Ghimire, and D.G. Hayes. 2017. Suitability of biodegradable plastic mulches for organic and sustainable agricultural production systems. HortScience 52:10-15.

Miles, C., R. Wallace, A. Wszelaki, J. Martin, J. Cowan, T. Walters, and D. Inglis. 2012. Deterioration of potentially biodegradable alternatives to black plastic mulch in three tomato production regions. HortScience 47:1270-1277.

Moore, R.C. 1963. Plastic mulch aids growth of young grape vines and cuttings. Biokemia 1(1):21-23.

Morra, L., E. Cozzolino, D. Cerrato, M. Bilotto, E. Mignoli, R. Coppola, V. Leone, M. Petriccione, M.S. Pasquariello, R. Parillo, F. Lanna, F. Mastrobuoni, and L. Zampilla. 2015. The effect of Mater-Bi based biodegradable mulch on production, organoleptic and nutritional quality of strawberry. In the results of the project to replace polyethylene mulch with the biodegradable ones in Mater-Bi for horticul- tural crops and under-green fruits: Agronomic and economic evaluations (in Italian). Programma di Sviluppo Rurale.

NASS. 2001. Noncitrus fruits and nuts 2001 summary. 18 July 2017. <http://usda.mannlib. cornell.edu/MannUsda/viewDocumentInfo. do?documentID $=1113>$.

NASS. 2017. Noncitrus fruits and nuts 2016 summary. 14 Aug. 2017. <http://usda.mannlib. cornell.edu/MannUsda/viewDocumentInfo. do?documentID $=1113>$.

Ngouajio, M., R. Auras, R.T. Fernandez, M. Rubino, J.W. Counts, Jr., and T. Kijchavengkul. 2008. Field performance of aliphatic-aromatic copolyester biodegradable mulch films in a fresh market tomato production system. HortTechnology 18:605-610.

Sivan, A. 2011. New perspectives in plastic biodegradation. Curr. Opin. Biotechnol. 22:422426.

Taparauskienė, L. and O. Miseckaitè. 2014. Effect of mulch on soil moisture depletion and strawberry yield in sub-humid area. Pol. J. Environ. Stud. 23(2):475-482.

Touchaleaume, F., L. Martin-Closas, H. AngellierCoussy, A. Chevillard, G. Cesar, N. Gontard, and E. Gastaldi. 2016. Performance and environmental impact of biodegradable polymers as agricultural mulching films. Chemosphere 144:433-439.

USDA. 2014a. National Organic Standards (NOS) \$205.206 Crop pest, weed, and disease management practice standard. 7 July 2017. <http://www.ams.usda.gov/AMSv1.0/ NOPOrganicStandards $>$.

USDA. 2014b. National Organic Standards (NOS) $\S$ 205.601(b)(2)(i-ii) Synthetic substances allowed for use in organic crop production. 19 July 2017. <https://www.gpo.gov/fdsys/ pkg/CFR-2009-title7-vol3/pdf/CFR-2009-title7vol3-sec205-601.pdf>.

USDA. 2017. Web soil survey. 14 Aug. 2017 $<$ https://websoilsurvey.sc.egov.usda.gov $>$.

Wang, S.Y., G.J. Galletta, M.J. Camp, and M.J. Kasperbauer. 1998. Mulch types affect fruit quality and composition of two strawberry genotypes. HortScience 33:636-640.

Washington State University (WSU) AgWeatherNet. 2017. AgWeatherNet. 7 July 2017. <http:// weather.wsu.edu/>.

Waterer, D. 2010. Evaluation of biodegradable mulches for production of warm-season vegetable crops. Can. J. Plant Sci. 90(5):737-743.

Weber, C.A. 2003. Biodegradable mulch films for weed suppression in the establishment year of matted-row strawberries. HortTechnology 13:665-668. 